Corrigenda to Volume 7, Number 3, p. 115-121

M. Lambropoulou • D. Tamiolakis • I. Venizelos • G. Alexiadis • G. Anastasopoulos • V. Limberis

G. Galazios • P. Tsikouras • M. Simopoulou • S. Nikolaidou • G. Petrakis • N. Papadopoulos

\title{
Induction of hepatic haematopoiesis with fibronectin expression by EMT stromal cells during the second trimester of development
}

In the original version of the article, at p. 119, some data reported in Table 2 and in the Results section were incorrect. The correct Table and text follow below. The Authors regret the error.

Table 2 Reactivity of Mabs with haematopoietic cells in human foetal liver

\begin{tabular}{|c|c|c|c|c|c|}
\hline \multirow[t]{2}{*}{ Cell type } & \multicolumn{2}{|c|}{ 1st trimester } & \multicolumn{2}{|c|}{ 2nd trimester } & \multirow[t]{2}{*}{$P$} \\
\hline & Average (cells $/ \mathrm{mm}^{2}$ ) & Range (cells/mm²) & Average (cells $/ \mathrm{mm}^{2}$ ) & Range (cells $/ \mathrm{mm}^{2}$ ) & \\
\hline Erythroid cells & $2890 \pm 740$ & $2300-4500$ & $3220 \pm 630$ & $2600-3900$ & 0.012 \\
\hline Granulopoietic cells & $32.5 \pm 17.8$ & $12-75$ & $60.3 \pm 29.2$ & $30-150$ & 0.017 \\
\hline Monocytes & $2.65 \pm 0.73$ & $1.8-3.9$ & $3.65 \pm 0.70$ & $2.1-4.8$ & 0.015 \\
\hline Blast cells & $45.7 \pm 15.2$ & $18-73$ & $53 \pm 18.7$ & 30-90 & 0.018 \\
\hline Megakaryocytes & $3.12 \pm 0.38$ & $2.1-4.2$ & $3.5 \pm 0.26$ & $2.5-4.1$ & NS* \\
\hline B-lymphoid cells & $4.12 \pm 0.52$ & $3.5-5.2$ & $4.52 \pm 0.48$ & $3.9-5.3$ & NS* \\
\hline
\end{tabular}

$N S$, no significant

18th to 22nd week of gestation (second trimester of gestation)

Morphological and immunohistological analysis of the liver samples during the second trimester showed: (1) A severe increase of erythroid cells by $20 \%$ (averaged: $3220 \pm 630$ cells $/ \mathrm{mm}^{2}$; range $2600-3900$ cells $/ \mathrm{mm}^{2}$ ) (Fig. $2 b)$, which was statistically significant $(P=0.012)$, favouring the second trimester. (2) Intense granulopoietic activity in the mesenchymal tissue of the portal fields extending into the sinusoids (Fig. 2c). The number of granulopoietic cells was approximately 2 times higher than that found in the first trimester (averaged: $60.3 \pm 29.2$ cells $/ \mathrm{mm}^{2}$; range $30-150$ cells $/ \mathrm{mm}^{2}$ ). Comparing the granulopoietic activity in the two trimesters we found a statistically significant difference $(P=0.017)$, favouring the second trimester. An elevation was observed for the monocytic lineage (averaged: $3.65 \pm 0.70$ cells $/ \mathrm{mm}^{2}$; range $2.1-4.8$ cells $/ \mathrm{mm}^{2}$ ). Comparing the two trimesters at the level of CD68 we found a statistically significant difference $(P=0.015)$ favouring the second trimester. The quantitative expression of CD34 by the vascular endothelial cells, the progenitor/stem haematopoietic cells and stromal progenitor cells was more intense in the mesenchymal portal tissue and the extending sinusoids (averaged: $53 \pm 18.7$ cells $/ \mathrm{mm}^{2}$; range 30-90 cells $/ \mathrm{mm}^{2}$ ) (Fig. 2d). Comparing the two trimesters at the level of CD34, we also found a statistically significant difference $(P=0.018)$ favouring the second trimester. No significant quantitative differences concerning megakaryopoiesis (averaged: $3.5 \pm 0.26$ cells $/ \mathrm{mm}^{2}$; range 2.5-4.1 cells $/ \mathrm{mm}^{2}$ ) (Fig. 2e) was observed between the two trimesters. Finally, a slight elevation was observed for the B lymphopoietic lineage (averaged: 4.52 \pm 0.48 cells $/ \mathrm{mm}^{2}$; range $3.9-5.3$ cells $/ \mathrm{mm}^{2}$ ) (Fig. 2f), while single cells expressing T-cell-specific/characteristic antigens were detected in the perivascular connective tissue in the portal triads and around the central veins (Table 2).

The distinction was confirmed by double immunostaining with FN and haematopoietic markers (myeloperoxidase, glycophorin C, CD34 (Qbend 10) and CD20), which demonstrated mutually exclusive expression on the two cell types (i.e., co-expression of either FN and erythroid series, or FN and myeloid series, or FN and stromal progenitors cells, or FN and B-lymphoid cells) in a total of 20 cases (Fig. 3). 